\title{
STUDIES ON NATURAL HABITAT AND CLONAL PROPAGATION OF Zeuxine regia (IRURAJA) AND Zeuxine flava (SANDARAJA)
}

\author{
By
}

Samangi Hewage

Thesis submitted to the University of Sri Jayewardenepura for the award of the Degree of Master of Philosophy in Botany on Plant Tissue Culture 


\section{Declaration}

The work described in this thesis was carried out by me under the supervision of Prof. W.T.P.S.K. Senarath and a report on this work has not been submitted in whole or in part to any university for any other degree or diploma

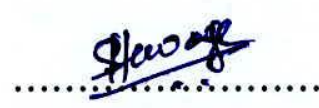

Samangi Hewage (BSc)
...!..!!................

Date 
I certify that the above statement made by the candidate is true and that this thesis is suitable for submission to the University for the Degree of Master of Philosophy.

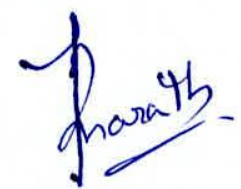

Prof. W.T.P.S.K. Senarath

Department of Botany

University of Sri Jayewardenepura

Nugegoda 
I hereby certify that all corrections, additions and amendments have been done accordance with the comments and suggestions of the examiners.

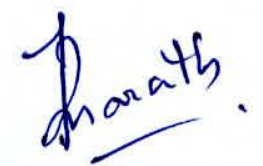

Prof. W.T.P.S.K. Senarath

Department of Botany

University of Sri Jayewardenepura

Nugegoda

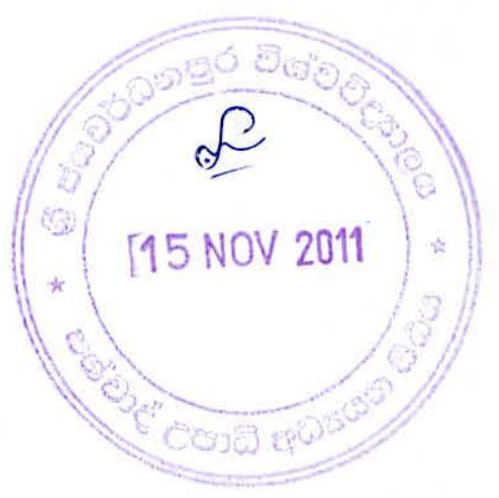




\section{TABLE OF CONTENTS}

Table of contents..............................................................................................

List of figures ....................................................................................................

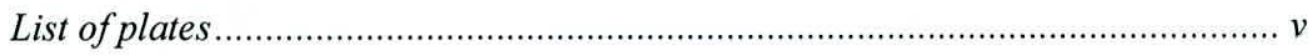

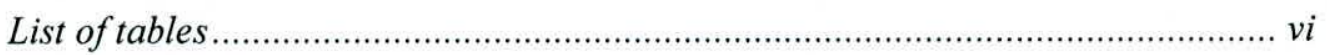

Acknowledgments................................................................................................ vii

Dedication .................................................................................................. ix

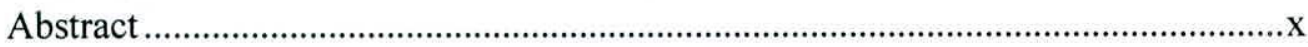

CHAPTER ONE: INTRODUCTION ..................................................................01-11

1.1 Family Orchidaceae ...................................................................................

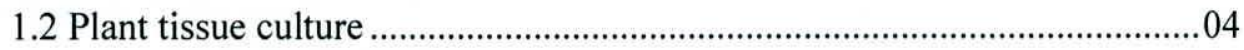

1.3 Habit of Zeuxine regia (Lindl.) Trimen (Iruraja)........................................05

1.3.1 Taxonomical classification of Zeuxine regia (Lindl.) Trimen ...........05

1.4 Habit of Zeuxine flava (Wall.) Trimen (Sandaraja) .....................................07

1.4.1 Taxonomical classification of Zeuxine regia (Wall.) Trimen.............07

1.5 Importance of mass propagation of Z.regia and Z. flava ...........................07

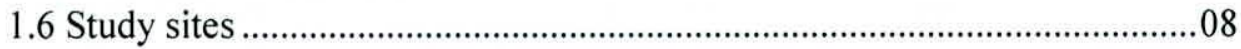

1.6.1 Kanneliya Man and Biosphere Reserve .............................................08

1.6.2 Peak Wilderness Sanctuary ……………………………………........09

1.7 Objectives of the study ............................................................................11

CHAPTER TWO: REVIEW OF LITERATURE ...............................................12-28

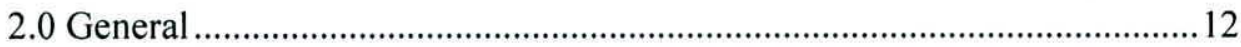

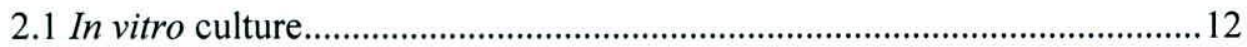

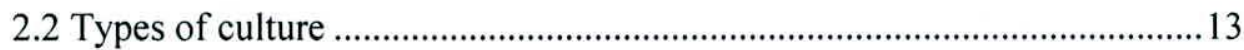

2.3 Vegetative propagation of Orchids .............................................................. 14

2.4 Outline of tissue culture of Orchidaceae....................................................... 16

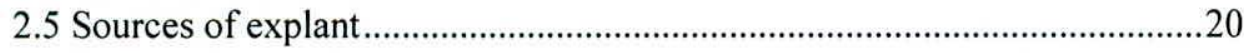

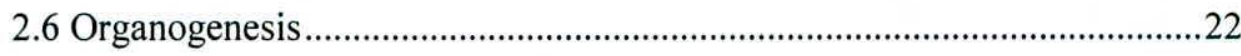




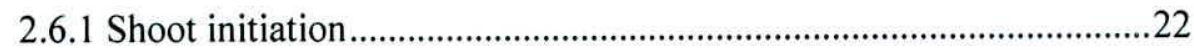

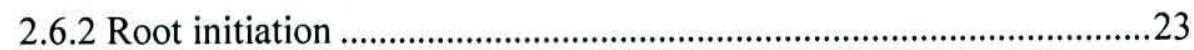

2.7 Somatic embryogenesis ..........................................................................24

2.7.1 Somatic embrygenesis in Orchids....................................................25

2.8 Medicinal importance of selected species.................................................27

CHAPTER THREE: MATERIALS AND METHODS ......................................29-42

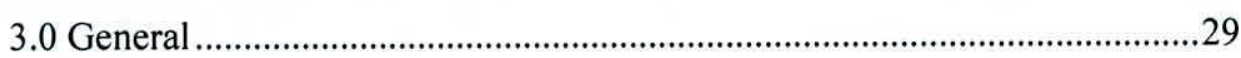

3.1 Comparison of habitats of Zeuxine regia and Zeuxine flava.................. 32

3.2 Effect of different growth regulators and basal media

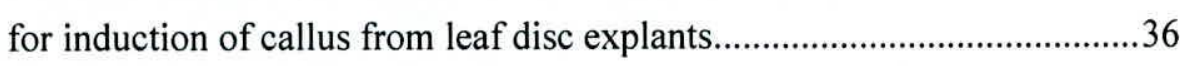

3.3 In vitro shoot induction of $Z$. flava and $Z$. regia

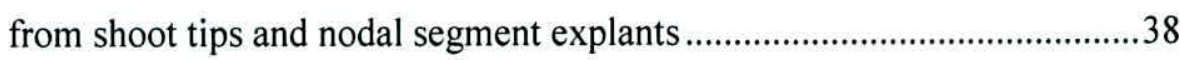

3.4 In vitro shoot multiplication of $Z$. flava and $Z$. regia .................................38

3.5 Effect of different growth regulators on root induction of

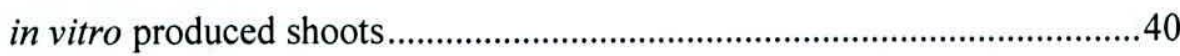

3.6 Effect of different potting mixtures on acclimatization ...............................40

3.7 Comparison of in vitro propagated plants with vegetatively propagated plants under greenhouse condition..............................................................42

3.8 Reintroduction of in vitro produced plants into natural habitat...................42

\section{CHAPTER FOUR: RESULTS AND DISCUSSION}

4.1 Comparison of habitats of Zeuxine regia, and Zeuxine flava 44

4.2 Effect of different growth regulators and basal media for induction of callus from leaf disc explants. . .50

4.3 In vitro shoot induction of $Z$. regia and $Z$. flava ........................................52

4.4 In vitro shoot multiplication of $Z$. flava and Z. regia.................................57

4.5 Effect of different growth regulators on root induction of in vitro produced shoots

4.6 Effect of different potting mixtures on acclimatization .65

4.7 Comparison of in vitro propagated plants with vegetatively propagated plants under greenhouse condition. 
CHAPTER FIVE: CONCLUSION 80-83

Micropropagation protocol for Z.flava ........................................................82

Micropropagation protocol for Z.regia ......................................................83

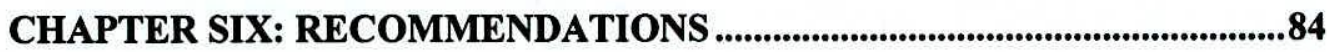

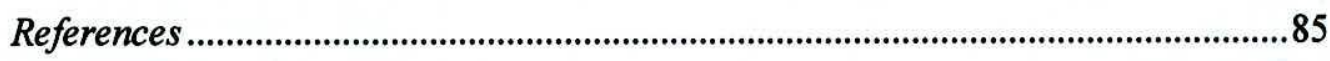

Appendices 


\section{List of figures}

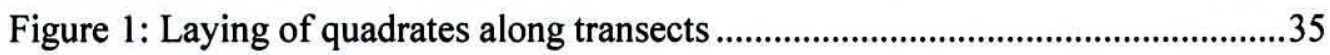

Figure 2: Dominant families associated with $Z$. regia ................................................45

Figure 3: Dominant families in areas without $Z$. regia .............................................46

Figure 4: Dominant families associated with $Z$. flava .............................................48

Figure 5: Dominant families in areas where $Z$. flava plants were not found ..............48

Figure 6: Variation in growth of tissue cultured plants and natural plants grown in the greenhouse over a period of one year .....................................75 


\section{List of plates}

Plate 1: (a) Habit of Z. regia (Lindl.) Trimen (Iruraja); (b) Habitat of Z. regia in Kanneliya MAB reserve

Plate 2: (a) Habit of Zeuxine flava (Wall.) Trimen (Sandaraja); (b) Habitat of Zeuxine flava in Kanneliya MAB reserve 06

Plate 3: Mother plants collected from Kanneliya MAB reserve, Peak Wilderness

Sanctuary and Haldummulla Nursery maintaining inside humid chambers 30

Plate 4: Swollen edges of leaf discs of $Z$. flava in 1/10 WPM. 51

Plate 5: Bud elongation of $Z$. flava in full-strength WPM medium supplemented with $2.0 \mathrm{mg} / \mathrm{L} \mathrm{BAP}$ and $1.0 \mathrm{mg} / \mathrm{L} \mathrm{2,4-D}$

Plate 6: (a) Elongation of axilary buds (b) Elongation of apical buds (after 5 days of incubation) of Z. flava in 1/10 WPM supplemented with $2.0 \mathrm{mg} / \mathrm{L} \mathrm{BAP}$ and $1.0 \mathrm{mg} / \mathrm{L} \mathrm{2,4-D}$

Plate 7: (a) Elongation of axillary bud: (b) elongation of apical bud of Z. regia in $1 / 10$ WPM supplemented with $2.0 \mathrm{mg} / \mathrm{L} \mathrm{BAP}$ and $1.0 \mathrm{mg} / \mathrm{L} \mathrm{2,4-D}$ after 12 weeks of incubation

Plate 8: Multiple shoot induction of $Z$. flava in MS medium supplemented with $0.1 \mathrm{mg} / \mathrm{L} \mathrm{NAA}, 1.0 \mathrm{mg} / \mathrm{L}$ BAP and $1.0 \mathrm{mg} / \mathrm{L} \mathrm{Kin}$ after 8 weeks of incubation 60

Plate 9: Formation of root nodules in Z. flava in multiple shoot induction medium. 64

Plate 10: Formation of root nodules in shoot induction medium without multiple shoots

Plate 11: Growth of in vitro produced plants in coconut husks medium 68

Plate 12: Growth of in vitro produced plants in leaf litter: top soil (1:1) medium .... 68

Plate 13: (a) Natural plant with flowers (b) In vitro produced plants with flowers... 75 


\section{List of tables}

Table 1: Diffferent basal media and growth regulator combinations used for callus induction from leaf disc explants of $Z$. flava and $Z$. regia

Table 2: Different combinations of BAP and Kin used with MS basal medium supplemented with $0.1 \mathrm{mg} / \mathrm{L}$ NAA

Table 3: Calculated IVI values for species with $Z$. regia ..... 46

Table 4: IVI values for species in areas where $Z$. regia plants were not found 47

Table 5: IVI values for species found with $Z$. flava. 49

Table 6: IVI values for species found in areas without $Z$. flava 49

Table 7: Time taken for bud elongation, mean shoot length from axillary buds and apical buds after six weeks

Table 8: Time taken for multiple shoot induction in different combinations of

$\mathrm{BAP}$ and $\mathrm{Kin}$ for Z. regia and Z. flava in MS basal medium supplemented with $0.1 \mathrm{mg} / \mathrm{L} \mathrm{NAA}$

Table 9: Mean number of shoots and shoot length in different weeks of incubation in MS medium supplemented with $0.1 \mathrm{mg} / \mathrm{L} \mathrm{NAA}, 1.0 \mathrm{mg} / \mathrm{L} \mathrm{BAP}$ and $1.0 \mathrm{mg} / \mathrm{L} \mathrm{Kin}$

Table 10: Mean number of root nodules, time taken for root nodule and hairy root formation in different growth regulator combinations in MS medium with $0.1 \mathrm{mg} / \mathrm{L} \mathrm{NAA}$

Table 11: Comparison of growth parameters for in vitro produced plants grown in two potting mixtures after six months

Table 12: Comparison of growth parameters of in vitro produced plants and natural plants after six months of growth in the greenhouse

Table 13: Comparison of growth parameters of in vitro produced plants and natural plants after six months of growth under natural conditions 


\section{ACKNOWLEDGEMENT}

First of all I wish to express my sincere gratitude to my supervisor Prof. (Mrs.) W.T.P.S.K. Senarath, Senior Lecturer, Department of Botany, Faculty of Applied Sciences, University of Sri Jayewardenepura for her relentless guidance, continuous supervision and critical comments for the completion of this study.

I wish to thank all academic and non-academic staff of the Department of Botany for helping me in various ways during this study.

I wish to express my regards to Dr. S.M.C.U.P. Subasinghe, Senior Lecturer, of Department of Forestry and Environmental Science of University of Sri Jayewardenepura for helping me in statistical analysis.

I wish to express my sincere gratitude to Department of Wildlife Conservation and Forest Department for granting me permission to collect mother plants from Peak Wilderness Sanctuary and Kanneliya Man and Biosphere Reserve.

I must thankfully remind Mr. Chithrasekara, Trekker in Kanneliya Man and Biosphere Reserve for the support given to me during my fieldwork, and maintenance team of Haldummulla nursery under Bandaranayake Memorial Ayurweda Institute for providing plant material for this study. With out them this study was not successful.

I wish to thank all non academic staff of the Department of Botany for helping me in various ways during this study.

My special thanks go to Mr. Sampath Wahala, Mr. Madhawa Wijerathne and Ms. Ayomi Witharana for their countless support and encouragement during my field work, without them it is impossible to complete this study.

I wish to give my special thanks to my friends Mr. S.N. Wijamuni, Mr. K.G.P.H Chandrasena, Ms. S. Kaluthota, Ms. A. de Silva, Mr. S. Gajanayake, Ms. S. Arangala, 
Ms. S de Silva and Ms. L. Weerasinghe for their support rendered to me to complete this work.

At last but not least I wish to express my deepest gratitude to my parents and my sister for helping me in various ways to make my study a success. 
Dedication

To my parents and my sister for their unconditional love, care and support to achieve goals in my life 


\title{
STUDIES ON NATURAL HABITAT AND CLONAL PROPAGATION OF Zeuxine regia (IRURAJA), AND Zeuxine flava (SANDARAJA)
}

\section{S. HEWAGE}

\begin{abstract}
Zeuxine flava and Zeuxine regia are two endangered medicinal plants belong to family Orchidaceae. The objectives of this study were to identify the natural distribution of these species in wet zone of Sri Lanka and associate tree species in their natural habitats, to develop a feasible mass propagation protocol and greenhouse establishment of the tissue cultured plants. Finally introduce the mass propagated plants back to their natural habitats.
\end{abstract}

During the ecological study in Kanneliya MAB reserve and Peak Wilderness Sanctuary it was observed that the common most families associated with $Z$. regia were Ebanaceae, Anacardiaceae and Dipterocarpaceae. There were only four tree species found in association with Z. flava. All these were represented by one stem and due to the higher diameter (dbh) Homalanthus populifolius become dominant.

No calli initiation was observed in any of the species, when the leaf discs were used as explants. Different basal media Murashige and Skoog (MS), Woody Plant Medium (WPM), and Knudson's C (KC) at different concentrations were supplemented with 2.0 mg/L Benzyle Amino Purine (BAP) and $1.00 \mathrm{mg} / \mathrm{L} \mathrm{2,4-dichlorophenoxyaceticacid} \mathrm{(2,4-}$ D) were used to initiate shoots from apical and axillary buds of $Z$. flava and Z. regia 
In the shoot initiation medium (SIM) (1/10 WPM supplemented with $2.0 \mathrm{mg} / \mathrm{L}$ BAP and $1.0 \mathrm{mg} / \mathrm{L}$ 2,4-D) bud initiation was observed in Z. flava and Z. regia within 5 days, but no multiple shoots were induced even after three subcultures. Elongated buds of $Z$. flava and Z. regia in SIM were transferred to MS basal medium supplemented with 0.1 $\mathrm{mg} / \mathrm{L}$ Naphthalene Acetic Acid (NAA), $1.0 \mathrm{mg} / \mathrm{L} \mathrm{BAP,} 1.0 \mathrm{mg} / \mathrm{L}$ Kinetin (Kin), induced multiple shoots of $Z$. flava, and mean number of shoots per shoot was $4.1 \pm$ 0.87. Z. flava cultures were further maintained up to 14 weeks for bud elongation. Multiple shoots were induced in Z. regia when MS medium supplemented with 0.1 $\mathrm{mg} / \mathrm{L} \mathrm{NAA}, 1.0 \mathrm{mg} / \mathrm{L}$ BAP and $0.5 \mathrm{mg} / \mathrm{L}$ Kin within 12 weeks time and mean number of $2.8 \pm 0.42$ shoots per shoot was observed. However, multiple shoots were not elongated further and root nodules were not produced in $Z$. regia. Therefore, further experiments were not carried out for Z. regia.

Z. flava shoots induced root nodules after ten weeks of incubation in SIM. Time taken to produce roots in multiple shoot induction medium was $5.7 \pm 0.67$ weeks. Further incubation ( $4.1 \pm 0.74$ weeks $)$ in the same medium produced hairy roots around the root nodules.

Mixtures of top soil and leaf litter (1:1) and coconut husks were used in this study for acclimatization. $100 \%$ survival was observed in both potting mixtures when plants were gradually introduced to the greenhouse after covering with a polypropylene bag and maintained in culture room temperature for seven days before being transferred to greenhouse. 
Mean number of leaves in in vitro produced plants was higher $(5.90 \pm 1.45)$ than those of vegetatively propagated plants $(4.50 \pm 0.87)$ after maintaining the same height in vitro produced plants and vegetative propagated plants for six months in greenhouse. Mean plant heights were also higher in in vitro produced plants $(6.63 \pm 2.5) \mathrm{cm}$ than vegetatively propagated plants. In vitro plants produced two to three multiple shoots per node after 6 months where no multiple shoot production in vegetatively propagated plants, indicating tissue cultured plants are more vigorous than natural plants.

In vitro produced plants grown under greenhouse conditions initiated floral spikes during early March, which is an unusual habit. Although under natural conditions, once the flower spike is fallen and plant dries off, in vitro produced plants do not died after falling off the flower spike, instead they initiated axillary buds and produced multiple shoots.

Mean number of leaves in in vitro produced plants after six months of growth in natural habitat were higher $(7.9 \pm 0.74)$ than natural plants. Mean height of the plant also higher in in vitro produced plants $(14.73 \pm 0.46 \mathrm{~cm})$.

In in vitro produced $Z$. flava plants, leaf texture and colour of the leaves were prominent than plants collected from the wild. Tissue cultured plants produced multiple shoots and flowers under greenhouse conditions. These factors indicate that mass production of $Z$. flava through tissue culture is possible for ornamental purposes and conservation of the species. 